Journal of

Applied Ecology

1999, 36,

$812-824$

\title{
The use of sighting data to analyse Iberian lynx habitat and distribution
}

\author{
LUÍS PALMA, PEDRO BEJA and MIGUEL RODRIGUES* \\ Universidade do Algarve, UCTRA, CCMAR, Campus de Gambelas, 8000 Faro, Portugal; and*Estrada \\ Senhora da Cabeça,4, 4930 Valença, Portugal
}

\section{Summary}

1. Over a large part of its very restricted and fragmented range, Iberian lynx Lynx pardinus occur in remote mountainous country at low density, where the only information about the species comprises records of incidental sightings obtained by inquiry. In this study we developed an approach for quantifying lynx-habitat relationships and distribution patterns from sighting data, using records from western Algarve (Portugal) in 1990-95.

2. Habitat was described in terms of land cover, topography, human disturbance and rabbit abundance, in $25-\mathrm{km}^{2}$ cells surrounding lynx sightings and at random locations within the study area.

3. Lynx sightings were consistently associated with predictable habitat features. Sighting probabilities estimated from a logistic regression model increased with the abundance of rabbits and the proportion of land covered by tall Mediterranean maquis, and declined with road density and the amount of developed land. This model identified correctly $85.7 \%$ of lynx sightings; at the same time only $20 \cdot 7 \%$ of the random locations were misclassified.

4. Indices of human presence were never associated positively with lynx sightings, suggesting that observation patterns were not influenced by the spatial distribution of potential observers.

5. Kriging was used to interpolate spatially between sighting probabilities derived from the logistic model in order to produce a map of sighting potential for the Iberian lynx in western Algarve. Jack-knife resampling assessed the accuracy of this map. Three well-defined areas of high sighting potential were identified, probably representing the lynx core areas in this region.

6. Our analysis of lynx sighting records suggests that these data may provide a first approximation to lynx habitat and distribution when further information is lacking. The application of this approach to other rare and reclusive species is discussed.

Key-words: conservation, geostatistics, logistic regression, Lynx pardinus, rabbits.

Journal of Applied Ecology (1999) 36, 812-824

\section{Introduction}

The Iberian lynx Lynx pardinus Temminck has recently been considered the most endangered wildcat in the world (Nowel \& Jackson 1996). This species only occurs in Portugal and Spain, with an estimated population of about 350 breeding females (Rodríguez \& Delibes 1992). The range of the Iberian lynx is currently very fragmented, with only

Correspondence: Dr Pedro Beja (fax + 351 89818353; email pbeja@ualg.pt). two populations larger than 200 individuals and occupying more than $2000 \mathrm{~km}^{2}$ (Rodríguez \& Delibes 1992). In the past, the lynx had a much wider range within the Iberian Peninsula, but this has decreased steadily since the 1950s (Delibes 1979; Palma 1980). Several factors may have contributed to this decline, but the main reasons are probably the destruction of Mediterranean scrubland and food scarcity (Delibes 1979). The Iberian lynx's staple prey is the rabbit Oryctolagus cuniculus L. (Delibes etal. 1975; Delibes 1980; Palma 1980), which has suffered widespread decline due to myxo- 
813

L. Palma,

P. Beja \&

M. Rodrigues

(C) 1999 British

Ecological Society

Journal of Applied

Ecology, 36,

812-824 matosis (Sumption \& Flowerdew 1985). Recently, outbreaks of viral haemorrhagic disease continue to depress rabbit populations (Villafuerte et al. 1994), reducing further the abundance of lynx food resources (Castro \& Palma 1996).

Details of the factors affecting lynx abundance and distribution are poorly documented, except for the well-studied Doñana population in south-western Spain (Palomares etal. 1996 and references therein). At Doñana, rabbit density and human disturbance have been shown to influence strongly the local lynx population (Delibes 1980; Palomares et al. 1991, 1996; Ferreras etal. 1992), but this information may be of limited value for the conservation management of the species elsewhere. Doñana is rather atypical in that lynx occur at high densities in a flat and coastal sandy area, whereas most other populations occupy mountainous country, where the animals tend to live at low density, probably wander widely and defy reliable observation. In these circumstances, the status of the species has been inferred from incidental sightings, obtained by asking the local human populations (shepherds, gamekeepers, hunters and farmers), together with field surveys aimed at detecting signs of lynx presence, such as scats and footprints (Rodríguez \& Delibes 1992; Oreja \& Vázquez 1996; Palma 1996). Many studies have provided rough accounts of lynx-habitat relationships in these areas, but these have generally been based on the subjective appreciation of patterns of sighting and sign occurrence.

In Portugal, the most important lynx population occurs in the remote mountainous areas of Algarve (Castro \& Palma 1996), where the animals are reclusive and probably live at low density (Palma 1996). Here, attempts to capture lynx for radiotelemetry have proved unsuccessful and little data can be obtained from sign surveys. As in other areas in Portugal, the main source of information for this population is through inquiries with local residents, which rarely yield more than a handful of incidental sightings of lynx per year. Despite this paucity and relatively poor quality of information available, conservation management measures for this population need to be taken. Urgent action is necessary to delineate boundaries for lynx conservation areas, select targets for habitat improvement, and to assess the environmental impact of new developments such as forestry projects and the construction of infrastructures (dams, roads, etc.). Moreover, the European Directive 92/43/EEC lists the Iberian lynx as a priority species, thus national conservation agencies are required to designate conservation areas for the species and to assess the potential negative impacts of human activities on their habitats and populations. This requires a good knowledge of lynx distribution patterns and habitat relationships, which need to be inferred from the available sighting data.

Previous research has shown that, despite several shortcomings, sighting data are a valuable source of information for rare and endangered wildlife species (Agee etal. 1989; Stoms etal. 1993). We sought to develop a quantitative approach for analysing the existing database of lynx observations in western Algarve in order to aid identification of the main habitat requirements and distribution centres. The specific objectives of this study were to determine if lynx sightings are associated with prey abundance, human activities and land cover characteristics in the surrounding area, and, if so, to model sighting potential as a function of habitat attributes. One aim of this modelling exercise was to derive a map of lynx sighting potential, from the spatial interpolation of sighting probabilities between locations where habitat attributes had been estimated. The results of the study were used to infer the most likely factors limiting the small Iberian lynx population inhabiting the uplands of Algarve, and to put forward some management and land-use recommendations regarding the conservation of this population. From a case study perspective, we also discuss the applicability of our approach to other animal populations in parts of their range where they are very rare.

\section{Study area}

The study was carried out in the rugged coastal and mountain regions of western Algarve (south-west Portugal), in an area of about $1500 \mathrm{~km}^{2}$ encompassing a cluster of lynx sightings (Fig. 1) separated from other clusters in eastern Algarve and southwest Alentejo by seemingly unsuitable habitat. Elevation ranges from approximately $0 \mathrm{~m}$ to $900 \mathrm{~m}$ a.s.l. The climate is of Mediterranean type; mean annual temperatures vary from $12 \cdot 2{ }^{\circ} \mathrm{C}$ to $17 \cdot 4^{\circ} \mathrm{C}$; and rainfall is concentrated between November and March, ranging from about $400 \mathrm{~mm}$ near the coast to over $1000 \mathrm{~mm}$ on the mountaintops. The natural vegetation of the area is primarily evergreen sclerophyllous scrubland (Rivas-Martínez et al. 1990), dominated at most locations by Cistus ladanifer L., and occupying abandoned farmland formerly devoted to extensive cereal cropping. In remote areas and on the steepest slopes there are patches of more mature Mediterranean vegetation, including cork oak Quercus suber L. woodlands and a tall and dense maquis dominated by Arbutus unedo L. and Erica arborea L. During the 1970s and 1980s large-scale afforestation with Eucalyptus globulus Labill. occurred in the uplands, replacing many abandoned agricultural fields and areas with natural vegetation that had been spared from past human activities. In rugged terrain agricultural 
814

Analysis of

Iberian lynx

sightings
(C) 1999 British

Ecological Society Journal of Applied Ecology, 36, $812-824$

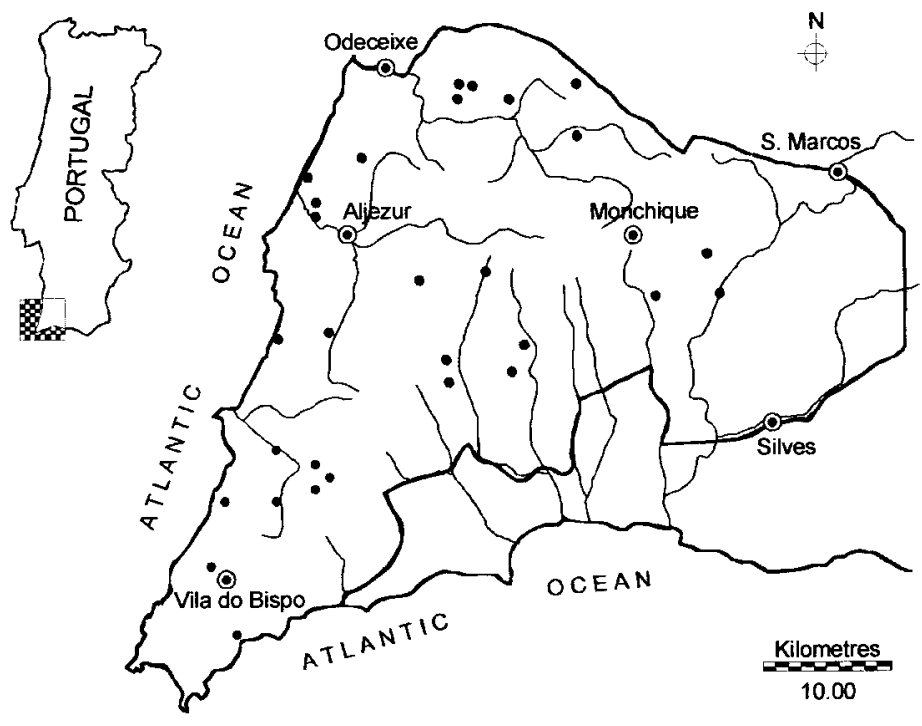

Fig. 1. Map of western Algarve (Portugal) showing the limits of the study area and the location of the 29 Iberian lynx sightings in 1990-95 analysed (black dots). The main villages are indicated by circled dots. The river network is also shown.

activities are now extremely reduced and human occupation is restricted to small villages and some cultivated valleys. The pattern changes at the coast, where there are wider agricultural areas, scattered habitation and some tourist centres.

\section{Methods}

\section{LYNX SIGHTING DATA}

Lynx sightings analysed in this study are included in a database compiled by the Portuguese conservation agency (Instituto da Conservação da Natureza), which incorporates records for all the country dating chiefly from the past three decades. Here we used a set of 29 lynx sightings from the region of western Algarve in the period between February 1990 and May 1995 (Fig. 1). Sighting locations were assigned to $1-\mathrm{km}^{2}$ Universal Transverse Mercator (UTM) grid cells to account for the maximum geographical uncertainty associated with a lynx observation. However, most locations were far more accurate than this, and indeed for many sightings the exact geographical position could be determined with virtually no error, with the help of the observer involved.

Most data were obtained during a survey carried out in Algarve and western Alentejo by one of us (L. Palma), from 1992 to 1994, which included more than 200 interviews with shepherds, farmers and hunters, among others. During the survey particular care was taken to ascertain sighting reliability from accurate descriptions of lynx aspect and behaviour. Only first-hand observations were accepted as reliable, and whenever possible the exact field locations where observations had occurred were checked with the observers. Most observation areas were searched for lynx signs (e.g. faeces and tracks), but the paucity of information obtained by this method made it unsuitable for use on a systematic basis. Results of the survey are reported in detail elsewhere (Palma 1996).

Although 29 sightings may be considered a rather small data set for inferring lynx habitat and distribution over an area of $1500 \mathrm{~km}^{2}$ in western Algarve, increasing the sample size by extending the study period would have been inadequate. This is because lynx sightings are reported at a very slow annual rate, and a long time would be needed for any significant increase in the data set. Studies based on past sightings of target species have to rely on the assumption that habitat conditions remain fairly constant over the period for which the observations were gathered (Agee et al. 1989; Stoms et al. 1993). This assumption could not be met in western Algarve had a period much longer than 5 years been selected, because of fairly rapid landscape changes (e.g. wildfires, forestry and desertion of agriculture). The study period (1990-95) thus represents a compromise between the needs for a data set as large as possible, and the requirement for stable habitat conditions.

\section{STUDY DESIGN AND HABITAT VARIABLES}

Sighting a lynx is to a large extent a random and rare event, thus it is likely that the precise location of an observation is mainly determined by the availability of observers, and not directly by the characteristics of the habitat at the site. However, 
provided lynx are occurring within areas of suitable habitat, and not randomly within the study area, lynx sightings should reflect habitat attributes in a broader area surrounding the sighting location. This hypothesis was investigated in this study, by determining habitat characteristics in $25-\mathrm{km}^{2}$ cells surrounding the 29 lynx sightings, and comparing these with the conditions surrounding an equal number of random locations within the study area. The $25-\mathrm{km}^{2}$ buffer was selected considering the size of annual home ranges occupied by male Iberian lynx in poor habitats (Ferreras et al. 1997). A relatively large area was selected compared with that used by animals living in optimal habitat (Ferreras etal. 1997), for Lynx species tend to show much enlarged home ranges at low density (Ward \& Krebs 1985; Knick 1990; Poole 1994). Random 1-km² UTM cells were located in a truly random manner, following the grid technique (Hays, Summers \& Seitz 1981). When random points fell within $25-\mathrm{km}^{2}$ cells surrounding lynx sightings, these locations were ignored and new ones selected.

For each $25-\mathrm{km}^{2}$ cell, 12 habitat variables were recorded as measures of land cover, physiognomy, human disturbance and prey abundance (Table 1). Land-cover data were derived from the interpretation of aerial photography (approximate scale 1:10000) from August 1995, using the point grid technique (Hays, Summers \& Seitz 1981). Vegetation cover was categorized in five broad structural types, assuming that details of floristic composition should be irrelevant to lynx. Classification of types on the aerial photography was straightforward, because of a previous detailed ground survey and characteristic texture and colour of the different categories. Landscape diversity was calculated by Shannon-Wiener's equation (Krebs 1989), using the proportions of different cover types.

Indices of land ruggedness, drainage density and road density were derived from 1:25000 maps. The index of land ruggedness was calculated by counting the number of times the lines on an overlay intercepted every fifth contour line $(50 \mathrm{~m}, 100 \mathrm{~m}, \ldots)$ on the topographic map. The overlay was a square representing an area of $25-\mathrm{km}^{2}$, where four radial lines running north-south, east-west, north-westsouth-east and north-east-south-west, had been drawn. Likewise, the indices of drainage density and road density were calculated by counting the number of interceptions with, respectively, the streams and paved roads represented on the map. Distance to the nearest village was calculated from the central point of the $25-\mathrm{km}^{2}$ cells, also on $1: 25000$ maps.

In relation to prey abundance only the rabbit was considered, for this is the staple food for the Iberian lynx (Delibes et al. 1975; Delibes 1980; Palma 1980). A single observer sampled rabbit availability in 49 days, between 28 April and 8 July 1996. For each $25-\mathrm{km}^{2}$ cell, the presence and relative abundance of rabbits were surveyed along $250-\mathrm{m}$ transects, one for each of 10 randomly selected $1-\mathrm{km}^{2}$ UTM grid cells. Transects were made along dirt roads following hill ridges, where preliminary observations had suggested that the presence of rabbits was most predictable. At each transect signs of rabbit activity (warrens, tracks, faecal pellets, scratches and observation of animals) were recorded and latrines were counted in a strip including $2 \mathrm{~m}$ beyond each side of the road. Latrines are special communal sites where rabbits deposit faecal pellets, in addition to deposit-

Table 1. Habitat variables used in the analysis of factors affecting the likelihood of Iberian lynx observation in western Algarve. See the study area section for a more detailed description of land cover types

\begin{tabular}{|c|c|c|c|c|}
\hline \multirow[b]{2}{*}{ Variables } & \multirow[b]{2}{*}{ Abbreviation } & \multicolumn{3}{|c|}{ Range of values } \\
\hline & & Minimum & Mean & Maximum \\
\hline \multicolumn{5}{|l|}{ Land cover } \\
\hline$\%$ of area with oak woodlands & $\%$ oak & 0 & 5 & 25 \\
\hline$\%$ of area with tall maquis & $\%$ maquis & 7 & 12 & 39 \\
\hline$\%$ of area with evergreen sclerophylous scrubland & $\%$ scrub & 7 & 36 & 71 \\
\hline$\%$ of area afforested & $\%$ afforested & 0 & 29 & 69 \\
\hline$\%$ of area with farmland & $\%$ farmland & 1 & 17 & 74 \\
\hline$\%$ of area with developed land & $\%$ developed & 0 & 2 & 11 \\
\hline Landscape diversity & Diversity & $0 \cdot 40$ & $0 \cdot 55$ & $0 \cdot 71$ \\
\hline \multicolumn{5}{|l|}{ Physiognomy } \\
\hline Index of drainage density & Drainage & $0 \cdot 65$ & $3 \cdot 60$ & $5 \cdot 60$ \\
\hline Index of land ruggedness & Ruggedness & $0 \cdot 90$ & $3 \cdot 70$ & $6 \cdot 00$ \\
\hline \multicolumn{5}{|l|}{ Human disturbance } \\
\hline Index of road density & Roads & $0 \cdot 00$ & $0 \cdot 16$ & $0 \cdot 70$ \\
\hline Distance to the nearest village, $\mathrm{km}$ & Distance & $0 \cdot 05$ & $1 \cdot 83$ & $4 \cdot 20$ \\
\hline \multicolumn{5}{|l|}{ Prey abundance } \\
\hline Average number of latrines per transect & Rabbit & $0 \cdot 00$ & $2 \cdot 50$ & $9 \cdot 20$ \\
\hline
\end{tabular}


816

Analysis of Iberian lynx sightings

(C) 1999 British

Ecological Society

Journal of Applied

Ecology, 36,

812-824 ing faeces apparently at random throughout their range (Sneddon 1991). Counts of faecal pellets have been widely used for estimating rabbit distribution and relative abundance (Rogers \& Myers 1979), this method being particularly appropriate for areas where the actual observation of individuals is difficult and the soil is generally unsuitable for recording tracks and scratches. However, in this case the dense and tall scrub precluded the counting of scattered pellets, hence only latrines were considered. An index of rabbit abundance was computed by considering the average number of latrines per transect.

\section{DATA ANALYSIS}

Logistic multiple regression (Hosmer \& Lemeshow 1989) was conducted using EGRET (SERC 1991) to predict the probability of lynx observation as a function of habitat conditions at $25-\mathrm{km}^{2}$ cells. However, some of the variables used for describing lynx habitat were intrinsically interdependent (multicollinearity), thus a substantial part of the information in one or more of these variables may be redundant and the conclusions drawn from the regression analysis may be ambiguous (Glantz \& Slinker 1990). Principal components regression (Glantz \& Slinker 1990) was used to compensate for unavoidable multicollinearity among the data. This method uses as independent variables the axis obtained from an ordinary principal components analysis (PCA). The principal components contain the same information as the original variables and have the benefit of being defined in a way so that they are mutually uncorrelated and that there is no redundant information between them. To improve the analysis further and to obtain simpler and more interpretable components, the PCA axes were rotated using the varimax criteria (Kim \& Mueller 1978).

The model building strategy included a preliminary analysis of the isolate effect of each rotated PCA component, using univariate logistic regression analysis (Hosmer \& Lemeshow 1989). Both Wald and likelihood ratio tests $\left(\chi^{2}\right)$ were computed, for they frequently provide different results. Because we sought to identify even tenuous correlates of lynx occurrence, all descriptors with $P$-values $<0.25$ in either test were retained for multivariate logistic regression analysis. To detect possible outliers in the data, influential observations were estimated from the delta-betas computed for each univariate regression model. A delta-beta is an approximation of the amount that an estimated regression parameter would change if a given observation was omitted from the regression fit, large changes indicating that the observation may fall off the pattern evident from the rest of the data (Glantz \& Slinker 1990; SERC 1991).
The variables retained in the preliminary scrutiny were then subjected to a forward stepwise procedure, in order to generate more parsimonious multivariate logistic models. All the variables for which the score test had $P$-values smaller than $0 \cdot 1$ were entered into the model, following the procedure available in EGRET (SERC 1991). The models developed were checked for biological plausibility, and variables were then entered into, or removed from, the models, in order to improve their goodness-of-fit. We also tested for the presence of nonlinearity and interactions between variables, following the procedures suggested by Hosmer \& Lemeshow (1989).

The significance of logistic models was ascertained from the likelihood ratio statistics, by comparing the deviance for the models of interest against the deviance for the model fitted only to the intercept $\beta_{\mathrm{o}}$ (Hosmer \& Lemeshow 1989). Classification tables were also used for assessing the goodness-of-fit (Hosmer \& Lemeshow 1989). For this, the estimated probabilities obtained from the regression models were converted to dichotomous $0-1$ data through specification of a cut-off point. Moving the cut-off points by increments of $0 \cdot 1$ along the $[0,1]$ probability interval allows estimates of optimal cut-off points to be made by identifying the values for which most successes are correctly classified, while minimizing the number of failures (Pereira \& Itami 1991). Classification accuracy of the model was then compared with that attainable by chance using Cohen's $\kappa$ (Siegel \& Castellan 1988; Brown \& Litvaitis 1995). Independent validation of the models by calculating classification error rates for data not used in the model building was not possible, because of the small sample sizes.

\section{MAPPING OF SIGHTING PROBABILITIES}

A map of sighting potential for the Iberian lynx in western Algarve was derived from the spatial interpolation between sighting probabilities estimated from the logistic model. Among the different interpolation methods available, kriging was used because this is probably the most adequate for constructing maps describing quantitative trends in a species abundance, as it takes into account the mathematical characteristics of the general structure of the spatial phenomenon studied (Maurer 1994; Villard \& Maurer 1996). Kriging is a weighed moving average technique, with weights depending on the spatial patterns of covariance between sampling points (Burroughs 1987). These patterns are obtained by fitting a theoretical mathematical model to an experimental variogram (Burroughs 1987; Maurer 1994), which represents the average degree of similarity between sampling locations as a function of geographical distance between them (Rossi 
et al. 1992). This model is the source of information about the average distance within which the samples remain correlated spatially (interpolation window), and the weights that must be used in the interpolation (Burroughs 1987). The variogram also contains information on the 'nugget variance', that is the spatial variability at distances smaller than the smallest sampling distance (Rossi et al. 1992). Variograms were produced with the program VARIOWIN 2.2 (Pannatier 1996), and interpolation was carried out using SURFER 5.01 (Golden Software 1994). Interpolation was only computed for locations where there were at least three data points occupying a minimum of two quadrants within the interpolation window.

Errors in mapping sighting probabilities through interpolation were assessed by jack-knife resampling (North \& Reynolds 1996). One observation was removed from the data, the remaining data were spatially interpolated, and the new map derived was used to estimate the probability of sighting lynx at the location of the observation omitted. This process was repeated for each observation in the data set, and the probabilities thus obtained were used to construct a new classification table, considering the same cut-off point as before. Cohen's $\kappa$ was used to assess classification accuracy of the interpolated estimates. We also regressed the sighting probabilities derived from the jack-knife approach on those estimated directly from the logistic model, to detect any significant departure from the expected relationship, $x=y$.

\section{Results}

INTERRELATIONS AMONG HABITAT VARIABLES

Principal components analysis of the habitat variables confirmed the presence of serious multicolli- nearity, the condition number for the first eigenvalue $\left(\phi=\lambda_{\max } / \lambda_{\min }=174 \cdot 3\right)$ being far above the threshold for concern (100). Loadings of the habitat variables on the rotated PCA axis are shown in Table 2. The varimax rotation was very successful in minimizing the loadings of each variable on all but one axis. The exceptions were the variables $\%$ scrub and \%afforested, which were both ascribed to axis I. The strong relationship between these two variables was probably because the areas of dry cereal farmland abandoned in the last decades either reverted to Cistus ladanifer L. scrubland, or were afforested with eucalyptus. Each axis from II to XI showed high loadings $(>0 \cdot 70)$ for a single habitat variable, and was almost not related to any other variable (loadings $<0.4$ ). Therefore, each of these axes may be thought to represent the portion of variability of a given habitat variable that is independent of the remaining variables. Axis XII did not show high loadings for any habitat variable, thus it was discarded from further analysis.

\section{COVARIATES OF LYNX SIGHTINGS}

The univariate logistic regression analysis (Table 3 ) showed a clear negative association between lynx sightings and road density (axis VIII), and a strong positive association with the abundance of rabbits (XI) and less so with tall maquis (IV). Vegetation diversity (II), land ruggedness (IX) and developed land $(\mathrm{X})$ showed weak $(P<0 \cdot 25)$ negative associations with lynx observations, but they were retained for further analysis.

The inspection of delta-betas for the detection of influential data points revealed that there was only one lynx sighting clearly falling off the pattern for the remaining data, at least for the axis related to the percentage cover by developed land. This observation was made close to a village, in an area with a

Table 2. Principal component loadings and explained variance (\% Var.) for varimax rotated PC axes I-XII describing the relationships between variables used to analyse lynx habitat in western Algarve. For each axis only the three variables with the highest loadings are given

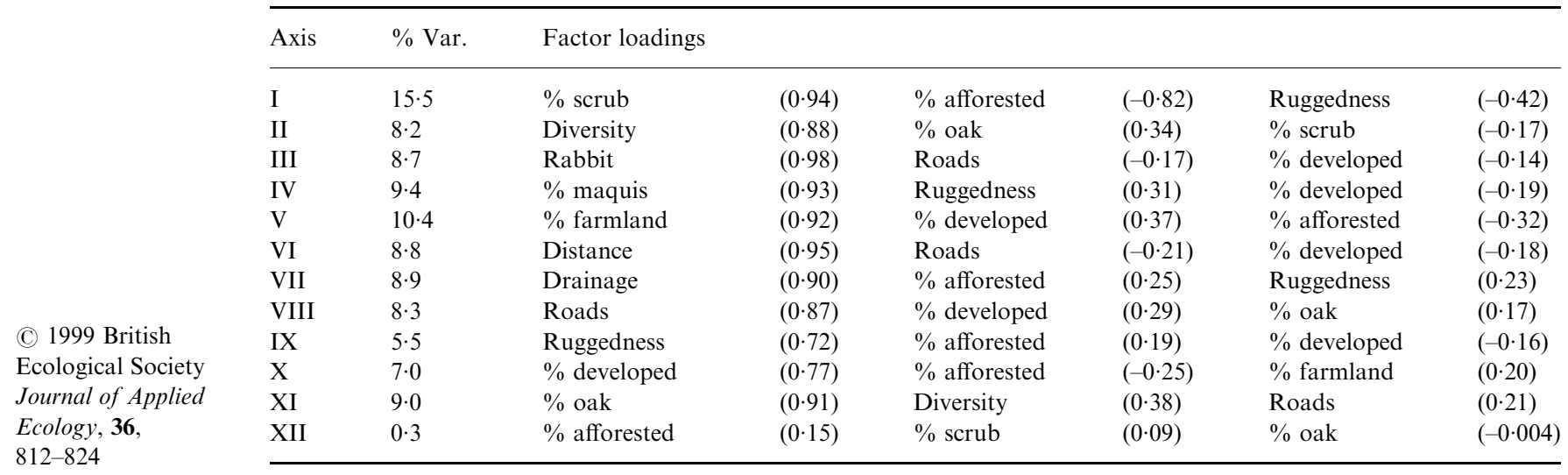


818

Analysis of Iberian lynx sightings

C) 1999 British

Ecological Society Journal of Applied Ecology, 36, $812-824$

Table 3. Effects of each habitat variable on the likelihood of lynx sighting in western Algarve, as assessed from the results of fitting a logistic univariate model to the varimax rotated principal components. Statistical significance of the habitat associations was obtained from the Wald test and the likelihood ratio test $\left(\chi^{2} ;\right.$ d.f. $\left.=1\right) . \beta=$ logistic regression coefficients. SE $(\beta)$ $=$ standard errors of $\beta$

\begin{tabular}{|c|c|c|c|c|c|c|}
\hline \multirow[b]{2}{*}{ Axis } & \multirow[b]{2}{*}{ Related variables } & \multirow[b]{2}{*}{ Coefficient $(\beta)$} & \multicolumn{2}{|l|}{ Wald test } & \multicolumn{2}{|c|}{ Likelihood ratio test } \\
\hline & & & $\beta / \mathrm{SE}(\beta)$ & $P$ & $\chi^{2}$ & $P$ \\
\hline I & $\begin{array}{l}\% \text { scrub }(+) \\
\% \text { afforested }(-)\end{array}$ & $0 \cdot 178$ & $0 \cdot 666$ & $0 \cdot 505$ & $0 \cdot 447$ & $0 \cdot 504$ \\
\hline II & Diversity & $-0 \cdot 394$ & $-0 \cdot 434$ & $0 \cdot 159$ & $2 \cdot 094$ & $0 \cdot 148$ \\
\hline III & Rabbit & $0 \cdot 745$ & $2 \cdot 250$ & 0.024 & $6 \cdot 279$ & $0 \cdot 012$ \\
\hline IV & $\%$ maquis & $0 \cdot 534$ & 1.778 & 0.075 & $3 \cdot 570$ & 0.059 \\
\hline $\mathrm{V}$ & $\%$ farmland & $0 \cdot 010$ & $0 \cdot 038$ & 0.969 & $0 \cdot 002$ & 0.969 \\
\hline VI & Distance & $-0 \cdot 025$ & -0.096 & 0.923 & $0 \cdot 009$ & 0.923 \\
\hline VII & Drainage & $0 \cdot 056$ & $0 \cdot 212$ & $0 \cdot 832$ & $0 \cdot 045$ & $0 \cdot 832$ \\
\hline VIII & Roads & $-0 \cdot 527$ & -1.799 & $0 \cdot 072$ & $3 \cdot 572$ & $0 \cdot 059$ \\
\hline IX & Ruggedness & $-0 \cdot 413$ & $-1 \cdot 467$ & $0 \cdot 142$ & $2 \cdot 288$ & $0 \cdot 130$ \\
\hline $\mathrm{X}$ & $\%$ developed & $-0 \cdot 483$ & $-1 \cdot 491$ & $0 \cdot 136$ & $2 \cdot 682$ & $0 \cdot 101$ \\
\hline XI & $\%$ oak & $-0 \cdot 200$ & -0.736 & $0 \cdot 462$ & 0.554 & 0.457 \\
\hline
\end{tabular}

much stronger human occupation than other sites where the species was sighted. When this observation was removed from the univariate analysis, a strong negative association between lynx and developed land emerged $(\beta=-1 \cdot 206 ; \beta / \mathrm{SE}(\beta)=-2 \cdot 461$; $P=0 \cdot 014)$, indicating that this data point may be an outlier. Because of this, the observation was discarded from further analysis.

The multivariate logistic model converged on a formulation including the axis related to rabbit abundance (III), cover by tall maquis (IV), road density (VIII) and cover by developed land (X) as the statistically significant variables $(P<0 \cdot 1$; Table 4). Clearly, sighting of a lynx is more likely in areas where food resources (rabbits) and cover (tall maquis) are abundant, and where human disturbance (roads and developed land) is reduced. This selection of variables would have remained identical, had we relaxed the inclusion criteria to consider variables with a score test $P<0 \cdot 2$. The model was satisfactory, because at the cut-off level yielding the largest percentage of correct classifications $(0 \cdot 5)$ it identified correctly $85 \cdot 7 \%$ of lynx cells; at the same time only $20.7 \%$ of the random cells were misclassified. Classification accuracy was greater than expected by chance $(\kappa=0.65, P<0 \cdot 001)$.

\section{MAPPING OF SIGHTING PROBABILITIES}

The variogram (Fig. 2) calculated from the spatial distribution of lynx sighting probabilities in western Algarve indicated that the maximum semi-variance occurs at lags of about $12 \mathrm{~km}$, and that points further apart than this tend to fluctuate in a pseudoperiodic manner. This result may derive from the spatial pattern of a species showing one or a few core areas, its abundance decreasing away from these areas. For lags smaller than $12 \mathrm{~km}$ the variogram was best represented by a Gaussian model, with a sill of 0.118 and a range of $9.2 \mathrm{~km}$, beyond which the observations may be treated as statistically independent. Therefore, the interpolation window was set equal to the range. The nugget effect obtained was small $(0 \cdot 012)$ but it was considered for

Table 4. Best multivariate logistic regression model describing the relationship between habitat conditions and lynx sighting probability in western Algarve (likelihood ratio $\chi^{2}=27 \cdot 115 ; P<0 \cdot 001$; d.f. $=4$ ). $\beta=$ logistic regression coefficients. SE $(\beta)$ $=$ standard errors of $\beta . \psi=$ odds ratio

\begin{tabular}{|c|c|c|c|c|c|c|}
\hline \multirow[b]{2}{*}{ Axis } & \multirow[b]{2}{*}{ Related variables } & \multirow[b]{2}{*}{ Coefficient $(\beta)$} & \multicolumn{2}{|l|}{ Wald test } & \multicolumn{2}{|c|}{ Odds ratio } \\
\hline & & & $\beta / \mathrm{SE}(\beta)$ & $P$ & $\psi$ & $95 \%$ CI \\
\hline & $\beta_{\mathrm{o}}$ & $-0 \cdot 263$ & $-0 \cdot 704$ & 0.482 & - & - \\
\hline III & Rabbit & $1 \cdot 161$ & $2 \cdot 524$ & $0 \cdot 012$ & $3 \cdot 193$ & $(1 \cdot 498,6 \cdot 806)$ \\
\hline IV & Maquis & 0.735 & $2 \cdot 093$ & $0 \cdot 036$ & $2 \cdot 085$ & $(1 \cdot 170,3 \cdot 714)$ \\
\hline VIII & Roads & $-0 \cdot 607$ & $-1 \cdot 711$ & 0.087 & 0.545 & $(0 \cdot 304,0 \cdot 976)$ \\
\hline $\mathrm{X}$ & $\%$ developed & -1.934 & $-2 \cdot 653$ & 0.008 & $0 \cdot 145$ & $(0.043,0 \cdot 479)$ \\
\hline
\end{tabular}


(C) 1999 British Ecological Society Journal of Applied Ecology, 36, 812-824

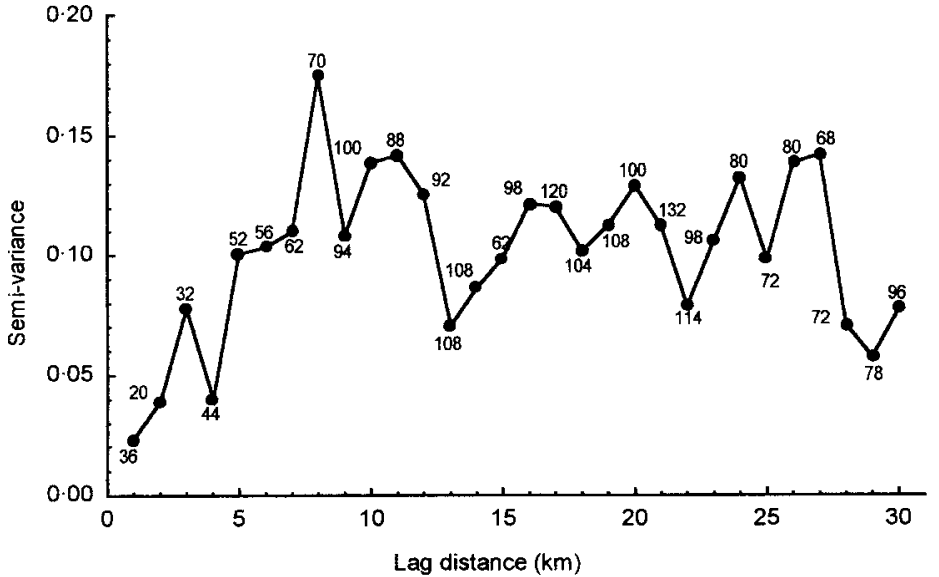

Fig. 2. Experimental variogram of lynx sighting probabilities derived from the logistic regression model in Table 4 .

spatial interpolation because matrix instability problems in kriging are often encountered when using a Gaussian model without a nugget effect (Pannatier 1996).

The sighting likelihood map generated by kriging was overlaid with sighting locations to facilitate comparisons between observed spatial patterns of lynx occurrence and the interpolated probabilities (Fig. 3). Another 57 interpolation maps were produced by jack-knife resampling, but in five cases the minimum number of data points necessary to carry out estimations was not available within the interpolation window of the observation removed from the data set. There was a significant linear relationship between the probabilities derived from the jackknife procedure and directly from the logistic model $\left(r^{2}=0 \cdot 40, F_{1,50}=34 \cdot 066, P<0.001\right)$, but the slope was significantly different from one $\left(b_{1}=0 \cdot 318\right.$, $\left.\mathrm{t}_{(50)}=-12.510, P<0.001\right)$ and the intercept different from zero $\left(\mathrm{b}_{0}=0 \cdot 225, \mathrm{t}_{(50)}=7 \cdot 255, P<0 \cdot 001\right)$. This was because kriging produced a smoothed trend surface, and thus small probability values were consistently overestimated and large values underestimated. Care should thus be taken when interpreting the map of sighting potential, for only the general spatial trends of high and low probability, but not the actual probability values, may be meaningful. In spite of this, the jack-knife probabilities classified correctly $80.8 \%$ of the observations as lynx sightings or random points, considering a cutoff point of $0 \cdot 5$. This classification accuracy is greater than expected by chance $(\kappa=0.62$, $P<0 \cdot 001)$

Given the limitations presented above, the map indicated the presence of three core areas (sighting probability $>0.5$ ), where most observations were carried out: (i) a south-western area, roughly corresponding to the hills of Espinhaço de Cão and the adjoining coastal gullies; (ii) a northern area, includ- ing essentially the river Seixe watershed; (iii) and a south-eastern area, encompassing the basin of the river Odelouca. The two southern areas seemed to be connected by a thin corridor with sighting probabilities from $0 \cdot 4$ to $0 \cdot 5$, along the southern slopes of the Monchique mountain, where some lynx observations were made, but they are separated from the northern area by a low-probability gap $(0 \cdot 2<P<0 \cdot 4)$. However, within this apparent gap there were some lynx observations close to the village of Aljezur.

\section{Discussion}

LIMITATIONS OF DATA AND SOME ASSUMPTIONS

The results presented here show a close agreement between the predicted distribution of lynx observations based on habitat criteria and their actual sightings. However, the study did not address directly the question of habitat selection by the lynx, any ecological inferences resting on the assumption that sightings should reflect an underlying habitat pattern. The main problems with this assumption are the uncertainty and error contained in sighting data, and the tendency for observations of rare species to be located in places most accessible to observers (Stoms et al. 1993). The first of these problems was probably eliminated in this study by considering only first-hand observations and carefully checking for consistency all sighting reports. The second problem was potentially more serious, for many sightings were clearly associated with human activities: observations from vehicles at night, during wild boar Sus scrofa L. hunts, or by shepherds guarding their flocks (Palma 1996). Considering this, it was accepted that sightings do not reflect habitat conditions in their immediate vicinity, but that they may be related to the landscape characteristics in a rela- 
820

Analysis of

Iberian lynx

sightings
(C) 1999 British Ecological Society Journal of Applied Ecology, 36, $812-824$

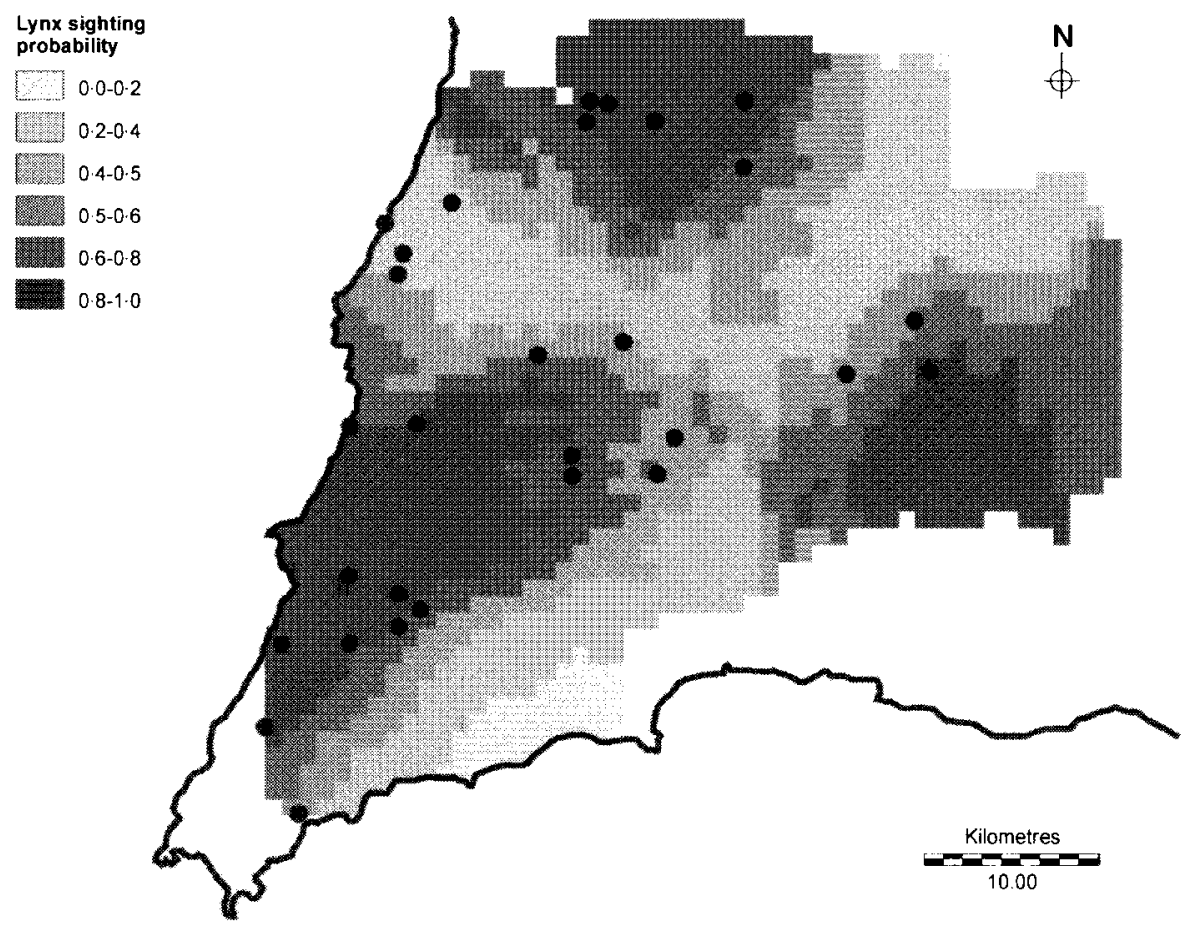

Fig. 3. Predicted distribution of lynx sighting probabilities in western Algarve (Portugal). The study area is mapped on a 1$\mathrm{km}^{2}$ UTM grid cell basis. Actual sightings of lynx in 1990-95 are indicated by a black dot.

tively large area $\left(25 \mathrm{~km}^{2}\right)$ surrounding the point of observation. It was assumed that this approach should reduce the bias associated with the uneven distribution of potential observers across the study area.

Circumstantial evidence suggests that the abovementioned potential errors probably did not affect the analysis greatly. First, sightings by different observers tended to occur within well-defined areas, suggesting that there was a consistent spatial pattern in lynx observations. This spatial pattern is not likely to have been caused by accessibility to observers for lynx sightings were negatively associated with habitat descriptors related to human presence (cover by developed land, road density and distance to the nearest village). Secondly, lynx observations displayed a consistent positive association with habitat variables that have been shown elsewhere to influence the species' distribution and abundance, namely the abundance of rabbits, reduced human presence and suitable vegetation cover (Palomares et al. 1991). These results give strength to the contention that lynx are generally occurring in areas of suitable habitat, and not randomly within the region. Thirdly, mapping of sighting probabilities was able to pinpoint clearly lynx core areas, where most observations were recorded, further emphasizing the inherent consistency of the data.

Results in the present study also indicate possible sources of error when interpreting lynx observa- tions. Probabilities obtained from the logistic regression model suggest that some sightings were carried out in areas where the habitat was poor. Reasons for this are unclear, but several non-exclusive hypotheses may be put forward to explain this pattern. Habitat evaluation was carried out from aerial photographs taken in August 1995 and field sampling was carried out in spring and early summer 1996, whereas the lynx data derives from February 1990-May 1995. Therefore, some habitat changes may have occurred, degrading habitat conditions in relation to the past situation. This may be the case in the region of Aljezur, where in July 1995 dramatic fires destroyed large areas where lynx had been observed, reducing suitable vegetation cover and possibly rabbit populations. Observations outside the core areas may be of juvenile dispersers seeking new areas to settle. Finally, it is also possible that there were some observations of old individuals that have managed to survive within a context of progressively degrading habitats.

\section{LYNX HABITAT IN MOUNTAINOUS AREAS}

Given the assumptions and limitations of sighting data discussed above, it is possible to draw some inferences about the factors influencing Iberian lynx distribution in the uplands of Algarve. The analysis in this study indicates that the presence of lynx is positively related to the abundance of rabbits and 
cover by tall maquis, and negatively related to road density and cover by developed land.

The close association between rabbits and the Iberian lynx has been acknowledged by several authors, leading to the suggestion that the decrease in the abundance of rabbits is one of the main causes for the widespread decline of the lynx (Rodríguez \& Delibes 1992; Castro \& Palma 1996). Likewise, in several North American lynx populations specializing on lagomorphs, prey abundance is a dominant factor determining population densities, through effects on home range size, spatial organization and reproductive rates (Ward \& Krebs 1985; Knick 1990; Poole 1994). Hence, it is likely that rabbit abundance may play a similar role in limiting lynx abundance and distribution within the study area. Transect counts of rabbit latrines in the uplands of Algarve showed a marked patchy distribution of the animals, with the areas of high sighting potential for lynx (Fig. 3) being roughly coincident with those where rabbits were most abundant. However, even within the areas with most rabbits their colonies seem to be relatively rare and sparsely distributed (M. Pais, L. Palma \& P. Beja, unpublished data). The low incidence of myxomatosis and the absence of viral haemorrhagic disease in upland Algarve (Simões 1995) suggests that the complex spatial patterns observed are not shaped primarily by disease outbreaks but may be related to habitat suitability. Following the progressive depopulation of rural uplands from the 1960s onwards, the mountains of Algarve have been overtaken progressively by eucalyptus afforestation and the recovery of natural vegetation. Rabbits show a strong negative selection against eucalyptus plantations and tall maquis, and they tend to live primarily at the edge of patches of early successional scrubland, where the right blend of food and cover may presumably be found (M. Pais, L. Palma \& P. Beja, unpublished data). At present, it seems that rabbits have difficulty in meeting their requirements within the upland landscape, being strongly dependent on scarce and scattered habitats. Therefore, conservation management directed at improving the quantity and quality of habitat for rabbits should have major positive effects on this lynx population.

The presence of lynx was also positively associated with the area of tall maquis, presumably because this vegetation type is the one offering the most secure cover to the animals. There is little published information, however, about resting site requirements of the Iberian lynx, although it is frequently assumed that the availability of these sites may limit the density and distribution of the species. Anderson (1990) found that bobcats Lynx rufus select rest sites with a dense vegetation cover, probably to obtain protection from extreme temperatures and wind, as well as for concealment and cover from predators.

Both road density and cover by developed land showed a strong negative association with the occurrence of lynx, thereby confirming previous information suggesting that lynx are very susceptible to human interference. In the Doñana National Park, lynx tend to be restricted to areas where human presence is reduced (Palomares etal. 1991, 1996), and most mortality is directly or indirectly caused by humans (Ferreras etal. 1992). Besides illegal trapping, road casualties have been indicated as the most important mortality factor for Doñana lynx (Ferreras etal. 1992). The negative relationship between roads and lynx is particularly interesting, and suggests that unroaded habitats are valuable for this species, as found elsewhere for other mammalian carnivores. Mladdenoff et al. (1995) showed that road density is one of the most important predictor variables in logistic regression models of wolf Canis lupus habitat in the Northern Great Lakes Region, with core pack areas located where road densities do not exceed $0.6 \mathrm{~km} \mathrm{~km}^{-2}$. Similar observations have been made in other regions, indicating that wolves are absent in higher road densities (Thiel 1985; Mech etal. 1988) or they occur in low numbers provided adjacent habitat is little roaded (Mech 1989). Strong negative responses to road densities have also been found for grizzly bears Ursus arctos horribilis by Mace et al. (1996) and for translocated mountain lions Felis concolor by Belden \& Hagedorn (1993). Clearly, more data on the relationship between Iberian lynx and roads are needed.

In this study no relationship was found between afforestation and lynx occurrence. This was rather surprising, because eucalyptus forestry, by far the dominant tree grown in this region, has been implicated in the decline of lynx populations (Castro \& Palma 1996). However, in the uplands of western Algarve the areas afforested are interspersed with patches of tall maquis and other natural vegetation. Nevertheless, it is likely that eucalyptus reduces habitat suitability for lynx, because rabbits tend to be absent from eucalyptus plantations (L. Palma, P. Beja \& M. Rodrigues unpublished data).

\section{USE OF SIGHTING DATA IN CONSERVATION STUDIES}

For many threatened, rare and reclusive species, scientific information to inform conservation action is often unavailable or restricted to little more than a meagre data set of incidental sightings scattered over large regions and long periods of time. Despite this shortage of data, critical management decisions are nearly always required for those species, although they are frequently based on subjective appreciation of whatever evidence is available. 
However, many conservation regulations have social and economic costs, and are thus open to much dispute and contest, in particular when they are not supported by hard scientific evidence. This is a case in point for the Iberian lynx.

Records of lynx sightings have formed the basis of extensive surveys (Rodríguez \& Delibes 1992; Castro \& Palma 1996), and over large areas little more information than this is likely to be obtained in the near future. However, this type of data has been dismissed as unreliable by many developers and decision makers, especially where there is conflict over the protection of lynx habitat and new developments, such as afforestation projects or the construction of infrastructures (dams, roads, etc.). This was the case, for instance, when sighting data were used for supporting the proposal of lynx conservation areas to the Natura 2000 network, created by the European Directive 92/43/EEC. Also, much public discussion has occurred recently over the crossing of the mountains of Algarve by a highway, and this was partly because the road was cutting important lynx areas, judged on the basis of sightings. Eventually, the route proposed by the government was changed so that it crossed the mountain in-between two clusters of lynx sightings (among other nature conservation reasons).

In this study we have carried out a detailed quantitative analysis of a typical data set of lynx sightings, composed of a small number of observations (29), obtained over a large region $\left(1500 \mathrm{~km}^{2}\right)$ and a long period (5 years). Despite the identified potential biases, including the disputable reliability of the observations, the analysis did succeed in associating lynx sightings with a predictable set of habitat conditions in the surrounding area. Furthermore, the influential habitat variables emerging from this research were those found to determine lynx abundance and distribution in areas where the species has been studied by more standard and powerful techniques (e.g. telemetry), suggesting that the results reflect underlying ecological processes and not mere spurious correlations. This supports the view that sightings may be used for supporting lynx conservation management, and that the approach described here may serve as a model for an expanded analysis of historical and continuing observations of lynx over geographical areas larger than the current $1500-\mathrm{km}^{2}$ study area. To improve confidence in the approach, however, it is important to undertake a more comprehensive validation of the procedure by applying it in situations where the actual use of habitat by lynx has been uncovered by more powerful techniques, such as radiotelemetry.

Geostatistical methods of spatial interpolation were used in this study to derive a map of sighting potential for lynx, whereas most other studies have relied on geographic information systems (GIS) for this purpose (Agee etal. 1989; Stoms etal. 1993). This was because some important variables influencing lynx distribution could not be easily mapped, such as rabbit abundance, and thus the necessary layers of information to derive a GIS map of sighting potential were not available in our case. This circumstance, however, is likely to be widespread in Iberian lynx studies, as well as in studies of other rare species living in remote parts of the world. Therefore, a geostatistical approach similar to ours may provide a valuable and objective way to evaluate the potential suitability of areas to support populations of endangered species, when more detailed data are not available. In this study, the lynx core areas identified through interpolation were roughly coincident with those identified previously from the subjective appreciation of sighting patterns and habitat suitability (Palma 1996).

In summary, this study adds support to the contention that sightings may indeed provide a valuable source of information about lynx distribution and habitat associations, giving credit to conservation recommendations and management decisions based on this type of data. We are confident that our approach may be used as a model to analyse similar data for other rare and reclusive species, providing a source of objective information on their habitat requirements and distribution patterns when additional data are lacking. However, monitoring schemes using more satisfactory techniques should be designed and implemented (Kendall et al. 1992; Zielinski \& Stauffer 1996) if adequate time and scientific information are available. Otherwise, we believe that thoroughly analysed observation records obtained from inquiries may provide a useful background for habitat protection and management.

\section{Acknowledgements}

This study was funded by the Instituto da Conservação da Natureza (ICN) and by the European Union (Project LIFE B4-3200/94/767). We are very grateful to Helena Ceia, Luís Roma Castro, Paula Abreu and Margarida Fernandes, the lynx conservation group of the ICN, for sharing some of the data used in this research and for useful discussions on lynx conservation issues. The interpretation of aerial photography was made at the Instituto Florestal (Lisbon), where it benefited from the expertise of Ana Fontes and many other colleagues. Maps were prepared with the help of Luís Jordão. Suggestions by Henrique Queiroga to study design and statistical analyses were deeply appreciated. Francisco Palomares, Francisco Moreira, Hans Kruuk, Maria Filomena Magalhães, Mike 

provided helpful comments and suggestions that improved earlier versions of the paper.

\section{References}

Agee, J.K., Stitt, S.C.F., Nyquist, M. \& Root, R. (1989) A geographic analysis of historical grizzly bear sightings in the North Cascades. Photogrammetric Engineering and Remote Sensing, 55, 1637-1642.

Anderson, E.M. (1990) Bobcat diurnal loafing sites in southeastern Colorado. Journal of Wildlife Management, 54, 600-602.

Belden, R.C. \& Hagedorn, B.W. (1993) Feasibility of translocating panthers into northern Florida. Journal of Wildlife Management, 57, 388-397.

Brown, A.L. \& Litvaitis, J.A. (1995) Habitat features associated with predation of New England cottontails: what scale is appropriate? Canadian Journal of Zoology, 73, 1005-1011.

Burroughs, P. (1987) Spatial aspects of ecological data. Data Analysis in Community and Landscape Ecology (eds R.H.G. Jogman, C.J.F. ter Braak \& O.R.F. van Tongeren), pp. 213-251. Pudoc, Wageningen, the Netherlands.

Castro, L.R. \& Palma, L. (1996) The current status, distribution and conservation of Iberian lynx in Portugal. Journal of Wildlife Research, 2, 179-181.

Delibes, M. (1979) Le lynx dans la Péninsule Ibérique: répartition et regression. Bulletin Mensuel de l'Office National de la Chasse, Numéro Special, Scientifique et Technique, Le Lynx, 41-46.

Delibes, M. (1980) Feeding ecology of the Spanish lynx in the Coto Doñana. Acta Theriologica, 25, 309-324.

Delibes, M., Palacios, F., Garzon, J. \& Castroviejo, J. (1975) Notes sur l'alimentation et la biologie du lynx pardelle, Lynx pardina (Temminck, 1824) en Espagne. Mammalia, 39, 387-383.

Ferreras, P., Aldama, J.J., Beltrán, J.F. \& Delibes, M. (1992) Rates and causes of mortality in a fragmented population of Iberian lynx Felis pardina (Temminck). Biological Conservation, 61, 197-202.

Ferreras, P., Beltrán, J.F., Aldama, J.J. \& Delibes, M. (1997) Spatial organisation and land tenure system of the endangered Iberian lynx (Lynx pardinus). Journal of Zoology, London, 243, 163-189.

Glantz, S.A. \& Slinker, B.K. (1990) Primer of Applied Regression and Analysis of Variance. McGraw-Hill International, New York, NY.

Golden Software Inc. (1994) SURFER for Windows User's Guide. Golden Software Inc., Golden, Colorado.

Hays, R.L., Summers, C. \& Seitz, W. (1981) Estimating Wildlife Habitat Variables. USDI Fish and Wildlife Service, Washington, DC.

Hosmer, D.W. Jr \& Lemeshow, S. (1989) Applied Logistic Regression. John Wiley \& Sons, New York, NY.

Kendall, K.C., Metzgar, L.H., Patterson, D.A. \& Steele, B.M. (1992) Power of sign surveys to monitor population trends. Ecological Applications, 2, 422-430.

Kim, J.-O. \& Mueller, C.W. (1978) Factor Analysis: Statistical Methods and Practical Issues. Sage Publications, Beverly Hills, CA.

Knick, S.T. (1990) Ecology of bobcats relative to exploitation and a prey decline in Southeastern Idaho. Wildlife Monographs, 108, 1-42.

(C) 1999 British Ecological Society Journal of Applied Ecology, 36, 812-824
Krebs, C.J. (1989) Ecological Methodology. HarperCollins, New York, NY.

Mace, R.D., Waller, J.S., Manley, T.L., Lyon, L.J. \& Zuuring, H. (1996) Relationships among grizzly bears, roads and habitat in the Swan Mountains, Montana. Journal of Applied Ecology, 33, 1395-1404.

Maurer, B.A. (1994) Geographical Population Analysis. Blackwell Scientific Publications, Oxford, UK.

Mech, L.D. (1989) Wolf population survival in an area of high road density. American Midland Naturalist, 121, 387-389.

Mech, L.D., Fritts, S.H., Radde, G.L. \& Paul, W.J. (1988) Wolf distribution and road density in Minnesota. Wildlife Society Bulletin, 16, 85-87.

Mladdenoff, D.J., Sickley, T.A., Haight, R.G. \& Wydeven, A.P. (1995) A regional landscape analysis and prediction of favorable gray wolf habitat in the Northern Great Lakes region. Conservation Biology, 9, 279-294.

North, M.P. \& Reynolds, J.H. (1996) Microhabitat analysis using radiotelemetry locations and polytomous logistic regression. Journal of Wildlife Management, 60, 639-653.

Nowell, K. \& Jackson, P. (1996) Wildcats: Status, Survey and Conservation Action Plan. IUCN, Gland, Switzerland.

Oreja, J. \& Vázquez, J. (1996) Situación del Lince Ibérico en Sierra de Gata. Doñana, Acta Vertebrata, 23, 91-98.

Palma, L. (1980) Sobre a distribuição, ecologia e conservação do lince ibérico em Portugal. I Reunión Iberoamerica de Zoólogos de Vertebrados, 1, 569-586.

Palma, L. (1996) O lince ibérico (Lynx pardinus) no Algarve e Sudoeste do Alentejo. Ciência e Natureza, 2, $7-14$.

Palomares, F., Ferreras, P., Fedriani, J.M. \& Delibes, M. (1996) Spatial relationships between Iberian lynx and other carnivores in an area of south-western Spain. Journal of Applied Ecology, 33, 5-13.

Palomares, F., Rodríguez, A., Laffite, R. \& Delibes, M. (1991) The status and distribution of the Iberian lynx Felis pardina (Temminck) in Coto Doñana area, SW Spain. Biological Conservation, 57, 159-169.

Pannatier, Y. (1996) VARIOWIN: Software for Spatial Data Analysis in 2D. Springer-Verlag, New York, NY.

Pereira, J.M.C. \& Itami, R.M. (1991) GIS-based habitat modeling using logistic multiple regression: a study of the Mt. Graham red squirrel. Photogrammetric Engineering and Remote Sensing, 57, 1475-1486.

Poole, K.G. (1994) Characteristics of an unharvested lynx population during a snowshoe hare decline. Journal of Wildlife Management, 58, 608-618.

Rivas-Martínez, S., Lousa, M., Diaz, T.E., FernándezGonzàlez, F. \& Costa, J.C. (1990) La vegetación del sur de Portugal (Sado, Alentejo y Algarve). Itenera Geobotanica, 3, 5-126.

Rodríguez, A. \& Delibes, M. (1992) Current status of the Iberian lynx Felis pardina Temminck 1824 in Spain. Biological Conservation, 61, 189-196.

Rogers, P. \& Myers, K. (1979) Ecology of the European wild rabbit, Oryctolagus cuniculus (L.), in Mediterranean habitats. I. Distribution in the landscape of the Coto Doñana, S. Spain. Journal of Applied Ecology, 16, 691-703.

Rossi, R.E., Mulla, D.J., Journel, A.G. \& Franz, E.H. (1992) Geostatistical tools for modeling and interpreting ecological spatial dependence. Ecological Monographs, 62, 277-314.

SERC (1991) EGRET: State-of-the-Art Epidemiological Computing. Statistics and Epidemology Research Corporation, Seattle, OR.

Siegel, S. \& Castellan, N.J. (1989) Nonparametric Statistics for the Behavioral Sciences. McGraw-Hill International, New York, NY.

Simões, R. (1995) O coelho-bravo, Oryctolagus cuniculus L., no Algarve. Viroses e outros factores limitantes. 
824

Analysis of Iberian lynx sightings
Licentiature Thesis. University of Trás-os-Montes e Alto Douro, Vila Real, Portugal.

Sneddon, I.A. (1991) Latrine use by the European rabbit (Oryctolagus cuniculus). Journal of Mammalogy, 72, 769-775.

Stoms, D.M., Davis, F.W., Cogan, C.B., Painho, M.O., Duncan, B.W., Scepan, J. \& Scott, J.M. (1993) Geographic analysis of California Condor sighting data. Conservation Biology, 7, 148-159.

Sumption, K.J. \& Flowerdew, J.R. (1985) The ecological effects of the decline in rabbits $(O$. cuniculus $\mathrm{L}$.) due to myxomatosis. Mammal Review, 15, 151-186.

Thiel, R.P. (1985) The relationship between road densities and wolf habitat suitability in Wisconsin. American Midland Naturalist, 113, 404-407.
Villafuerte, R., Calvet, C., Gortázar, C. \& Moreno, S. (1994) First epizootic of rabbit haemorrhagic disease in free-living populations of Oryctolagus cuniculus at Doñana National Park, Spain. Journal of Wildlife Diseases, 30, 176-179.

Villard, M.-A. \& Maurer, B.A. (1996) Geostatistics as a tool for examining hypothesized declines in migratory songbirds. Ecology, 77, 59-68.

Ward, R.M.P. \& Krebs, C.J. (1985) Behavioural responses of lynx to declining snowshoe hare abundance. Canadian Journal of Zoology, 63, 2817-2824.

Zielinski, W.J. \& Stauffer, H.B. (1996) Monitoring Martes populations in California: survey design and power analysis. Ecological Applications, 6, 1254-1267.

Received 11 April 1998; revision received 6 April 1999 